\title{
1. Big Science and Research Infrastructures in Europe: History and current trends
}

\author{
Katharina C. Cramer, Olof Hallonsten, \\ Isabel K. Bolliger and Alexandra Griffiths
}

\section{INTRODUCTION}

This book is about two widely used but scarcely analyzed current phenomena: Big Science and Research Infrastructures (RIs). Both concepts are enormously important in European science, technology and innovation policy, judging by the political "hypes" around them (Hallonsten 2020a) and because of their evident inherent forces for European integration and multilateral cooperation and diplomatic progress (Krige 2003; Papon 2004; Hallonsten 2014; Cramer 2017). On the basis of the current use of the term Research Infrastructures and the historical and current use of the term Big Science, it can be established that the categories of things that the two describe are very wide and partially overlapping. Classic examples of Big Science, like particle accelerators and telescopes, are certainly infrastructures used for scientific research, and hence in some rudimentary sense RIs. Therefore, the politics and history of the two are inseparable, especially perhaps in a European context where the need and will for collaboration, coordination and integration among a varying number of countries make most costly and advanced facilities and resources for scientific research unavoidably political.

While the term Research Infrastructures seems to represent a more recent phenomenon, the era of Big Science dates back to at least the early Cold War. After World War II, investments in science and technology soared due to the powerful and partly horrendous wartime demonstrations of the potential of science and technology to alter and shape geopolitics, the postwar economic growth as well as the eagerness of governments to invest in national competitiveness, and the advancement of ideals of a modern and rationally planned society. Major, large-scale and goal-oriented programs to develop weapons, energy production, transport systems, and the engineering of new materials 
for use in military and civilian technologies, were initiated in all industrialized countries. Big Science became both a role model and a deterrent, and its connections with nuclear energy, nuclear weapons and superpower competition between the United States (US) and the Soviet Union tied it closely to the bipolar geopolitical world order (Galison and Hevly 1992; Hallonsten 2016a). Accelerators for particle physics experiments were built on both sides of the Iron Curtain to demonstrate superiority over the other superpower, and research and development (R\&D) programs with peaceful and military motivations were institutionally entangled in governmental research laboratories and followed the cycles of growth and decline of each other and the greater geopolitical tides of hostility and détente (Greenberg 1967/99; Hallonsten and Heinze 2012).

Big Science in Europe also evolved very much in accordance with the political logic brought about by the historical developments during the Cold War, including the arms race, but perhaps most importantly, the need to collaborate to secure long-term peace on the continent as well as the desire for restoration of national sovereignty (Krige 2006). In this regard, the launch of the European Organization for Nuclear Research (CERN), a collaborative nuclear and particle physics laboratory, in the 1950s was Europe's first postwar experience in large-scale cooperation (Hermann et al 1987, 1990; Krige 1996). Other examples of Big Science in Europe, extensively studied by historians and sociologists, are the European Southern Observatory (ESO) (Blaauw 1991; Madsen 2012), the Institut Laue-Langevin (ILL) (Pestre 1997; Jacrot 2006; D'Ippolito and Rüling 2019; D'Ippolito and Rüling, ch 11 in this volume), the European Synchrotron Radiation Facility (ESRF) (Cramer 2017, 2020; Simoulin 2012) and the German Electron Synchrotron (DESY) (Heinze et al 2015a, 2015b, 2017). Attention has also been paid to the broader historical, political and macrosociological developments of Big Science in Europe (Krige 2003; Hallonsten 2014, 2016a; Cramer 2020).

In a scholarly meaning, however, Big Science was defined retrospectively. The early use of the concept was by practitioners and commentators who analyzed statistical manifestations of a growing scientific enterprise (Price 1963/86) and warned for the most extreme consequences of team- and program-oriented research, such as bureaucratization at the expense of creativity and academic freedom (Weinberg 1961, 1967). As a conceptual label in the history of science, Big Science got its breakthrough in the early 1990s, initially as an umbrella term for investigations of the particular dynamics of science and technology in the US and Europe during the Cold War. In this context, Capshew and Rader (1992: 22) proposed a differentiation between "big science" and "Big Science", with the latter being "a rhetorical construction" pointing to the particular dynamics of large-scale research following the end 
of World War II, and the former a generic label used to illustrate the growth of science in size or numbers in the twentieth century.

In this book we deal with Big Science, capitalized. Our interest lies not in the general growth of science in society, but particular forms of science that usually require large-scale instrumentation. We do, however, note that throughout the most recent decades, the concept of Big Science has become commonplace in the history and sociology of science and it has thus also grown remarkably broad and heterogeneous: Nowadays, things typically identified as Big Science are still manifest features of science and innovation systems, although their expressions are less conspicuously "big" and less distinctly connected to military interests and geopolitics (Hallonsten 2016a).

Looking at current European science and innovation policy, especially as represented in the ubiquity of documents, reports and policy memoranda produced by the European Union (EU), the current era in the early twenty-first century seems to be an era of RIs. In the past two to three decades, the EU has undertaken a comprehensive policymaking effort to strengthen the global competitiveness of its common market by support of science, technology and innovation for growth, sustainability and prosperity. RIs are defined by the EU as "facilities, resources and related services that are used by the scientific community to conduct top-level research in their respective fields" (European Council 2009: 4). The concept has become very important as various projects, organizations and installations are branded as RIs in policy documents and EU legislation, and identified as crucially important for the long-term competitiveness of European science and innovation.

Yet, as a concept, Research Infrastructures is very wide and very varied, and there are no definitions available that meet the rudimentary standards of scholarly analysis (Hallonsten 2020a). An intuitive or traditional interpretation of research infrastructures (non-capitalized) could be comparably large and centralized physical and technically advanced resources that are used for experimental research in the natural sciences. This would also mean significant overlap with a traditional or intuitive interpretation of Big Science (capitalized). But the term also has a different meaning and there is hence reason to separate "research infrastructures" and "Research Infrastructures", similarly to what Capshew and Rader (1992) suggested with regard to "Big Science" and "big science" (above). In this regard, it needs to be acknowledged that the concept Research Infrastructures (capitalized) is very much connected to policymaking in Europe, where it ostensibly refers to a rather wide collection of entities that include some typical Big Science but also physically distributed resources for research, such as computing networks or large collections of data or physical objects, with user communities in the social sciences and humanities; or mobile vehicles, like aircrafts for atmospheric testing or icebreaker ships for polar expeditions. The collections of projects and organizations in the 
many roadmap documents that are produced by European bodies and national agencies in several European countries to coordinate RIs in Europe show a remarkable variety in this regard (see below and Bolliger and Griffiths, ch 5 in this volume), as do the to date 21 organizations that have been granted status as the European Research Infrastructure Consortium (ERIC) (Moskovko, ch 6 in this volume).

There is, hence, a certain overlap between the concepts Big Science and Research Infrastructures (both capitalized), but both concepts can also be given broader interpretations and extend beyond big physical installations, to include mission-oriented research in larger organizations, such as genomics projects, space programs and explorer missions. The two concepts are, however, also connected by history, and more specifically, European history: The recent emergence of RIs as a policy area in Europe follows a longer historical trajectory where Big Science has had a key role, within a framework of (geo)politics of the European continent and its forces of integration and disintegration throughout the post-World War II era (Cramer, ch 3 in this volume). A historical inability of European countries to agree and align their interests in intergovernmental, collaborative large-scale science projects (see Section 2), and a perceived need of the European Economic Community (EEC) and its successor the EU (these acronyms are used alongside each other throughout this chapter, to denote the community of Europe before and after the 1992 Maastricht Treaty) to actively engage in research and innovation policy, evidently produced the current policy "hype" around RIs in Europe, and launched the policy area itself.

\section{A BRIEF HISTORY OF BIG SCIENCE AND RESEARCH INFRASTRUCTURES IN EUROPE}

As noted, the phenomenon of Big Science dates back to the early Cold War period when science and technology became increasingly important for national power and security policies. The technology- and science-based conduct of war in the early-to-mid-twentieth century and the practical goal-oriented use and development of science and technology within large-scale research projects funded by governments in this era tied these projects closely to military, political and economic interests. Moreover, with the emerging (geo)political tensions between the US and the Soviet Union, the two powers sought to compete also beyond territorial gains and diplomatic successes, and large scientific projects became instruments for long-term security ambitions, and symbols of scientific and technological capability (Greenberg 1967/99; Krige 2006).

Fundamental research in physics, with its clear connection to nuclear energy and weapons development, got a role as essential contributor to both 
US-American and Soviet military power during the Cold War. The space programs on both sides of the Iron Curtain also became integrated parts of the so-called Military-Industrial Complex, to which "scientific" could well be added as a third ingredient (Hallonsten 2016a: 43ff.; Giroux 2007). Moreover, at that time, the construction of ever more complex and costly instruments became a decisive factor for success and progress in scientific fields such as ground-based astronomy and nuclear/particle physics. For instance, the ever larger accelerators for nuclear/particle physics demanded ever larger governmental investments (Hoddeson et al 2008; Greenberg 1967/99).

In the immediate post-World War II years, Western Europe was marked by destruction and an unstable political situation. But the agreement on the Schuman plan, the establishment of the European Coal and Steel Community and the Marshall Plan created a political climate in favor of collaboration. The 1957 launch of the Common Market and the European Atomic Energy Community, by the Treaties of Rome, institutionalized intergovernmental collaboration in some specific areas, but it did not include science and technology (beyond nuclear energy) (Guzzetti 1995; Krige and Guzzetti 1997; Tindemans 2009; Hallonsten 2014).

It was not until the 1970s that the EEC expanded its policy areas into the promotion of science and technology. The initiation of industry-oriented programs, to increase competitiveness in specific sectors, was certainly triggered by the economic downturn and the reevaluation of the science and innovation policy doctrines that had been in place since the war (Elzinga and Jamison 1995; Guston 2000). The first Framework Programme for Research and Technological Development in 1984 and the signing of the Single European Act in 1986 constituted further important milestones with regard to the establishment of a more coherent and strategic research policy agenda of the EEC (Guzzetti 1995: 83-6; Papon 2004: 69-70). Yet, although at the end of the 1980s "[t]he mechanics for the implementation of a European research policy were practically put in place" (Papon 2012: 49), active partaking of the European Commission in maintaining and developing a broad research base in Europe began only several decades later.

The establishment of CERN in 1954 by 20 states was Europe's first experience in intergovernmental collaborative large-scale research. Its creation was a particular symbol for a renewed Western (political) unity that should strengthen regional collaboration and political integration (Krige 2003, 2006). A large number of intergovernmental large-scale research collaborations followed in the coming decades: ESO in 1962, the European Space Research Organisation (ESRO) in 1962, the European Space Vehicle Launcher Development (ELDO) in 1964, ILL in 1967, the European Molecular Biology Laboratory (EMBL) in 1973 and ESRF and the European Transonic Wind Tunnel (ETW) in 1988. All these projects were based on intergovernmental 
agreements signed by a varying number of countries; a mode of cooperation that became known as "variable geometry" or "Europe à la carte" (Papon 2009: 36; Guzzetti 1995; Ulnicane, ch 4 in this volume) and also extended beyond collaborative large research projects, to multilateral coordinating activities such as the European Cooperation in Science and Technology (COST), the European Research Coordination Agency (EUREKA) and high-technology and industry-related joint ventures such as the multinational aerospace corporation Airbus or the launch vehicle Ariane (Roland 1997: 356; Peterson 1997; Papon 2004: 68).

In spite of their formal detachment from common EEC and EU policymaking, large projects in science and technology came to play important roles in European history and the European integration process in the second half of the twentieth century. In the analysis of historians Misa and Schot (2005: 2), "scientific and technical cooperation among national states in Europe proved to be a catalyst for political integration, and a compensation for setbacks in the political area" during the 1960s, as well as an answer to the threat of Soviet and US dominance. The successful establishment of European space efforts, such as the European Space Agency, Ariane and Airbus are also identified as significant for the construction (and consolidation) of European power and a European community: "These large technological projects generated a practical sense of what Europe was about, while producing highly visible outcomes such as Ariane and Airbus that served as symbols for European power and might" (Misa and Schot 2005: 14).

The creation of the European Research Area (ERA) in the early 2000s certainly was a key milestone within a broader policy approach to improve the global role of the EU in science and technology, and the globalized knowledge-based economy. The broader development of EU research policy in the decade preceding the launch of ERA can be interpreted as a shift of focus to innovation, which meant a broadening in scope beyond industry-related issues and to a more systemic view with a broader set of actors and institutions included at the receiving end of policymaking (Elera 2006; Hallonsten 2020a). In this context, large-scale research projects, eventually labelled Research Infrastructures in EU policy documents, got increased attention from EU policymakers and administrators. According to EU policy documents published in the first decade of this century, RIs cover a variety of different large-scale research projects from national as well as collaborative efforts, single-sited and distributed projects, or single large instruments, networks and databanks in various disciplines and scientific fields (natural sciences and humanities alike) (see below).

RIs had gotten some attention already in earlier Framework Programmes, such as in the second (in place 1987-91) where 30 million ECU was allocated for facilitating access to RIs. But the real breakthrough for RIs in EU policy- 
making came with ERA and the 2002 creation of the European Strategy Forum on Research Infrastructures (ESFRI). The early 2000s was a period when Europe experienced especially dire difficulties to agree and push forward collaborative projects, particularly in comparison with its direct competitors on a global level (Japan and the US).The basic idea behind ERA was to provide favorable conditions for all steps of the innovation process, including research at RIs that seemingly possess a strong strategic importance for the achievement of the goals set forth in the ERA strategy (Hallonsten 2020a). ESFRI got the role of a discussion forum and consultancy body to the European Commission, with the primary mandate of preparing and publishing a RI roadmap, which came out in a first edition in 2006 and was followed by updates in 2008, 2010, 2016 and 2018 (Bolliger and Griffiths, ch 5 in this volume). The most evident result of its policy advisory role to the European Commission has been the launch of a completely new organizational form, ERIC, created in 2009 by European legislation (Moskovko et al 2019; Moskovko, ch 6 in this volume). Nonetheless, in spite of the emerging and growing policy role of the EU in collaborative large-scale research projects and the introduction of the ERIC legislation, these projects are still built on intergovernmental ad hoc agreements and voluntary participation (Krige 2003). The creation of the European X-Ray Free-Electron Laser (European XFEL) in 2009, the Facility for Antiproton and Ion Research (FAIR) in 2010 and the European Spallation Source (ESS) in 2009 are only a few of the most recent examples in this regard (Cramer, ch 3 in this volume; Hallonsten 2002b).

Reconciling from above, all these historical and recent examples of collaborative large-scale research in Europe have in common that alliance building has been key to bring the projects into being. Most of the projects were initiated by a very small number of countries, often the politically most powerful, such as France, (West) Germany or the United Kingdom, who entered into basic agreements to which other countries were invited to join. In the most recent years, large-scale research collaborations in Europe also increasingly include Central Eastern European countries formerly under communist rule, and countries from outside the EU or continental Europe, such as Russia, India and South Africa. The political realities of these collaborations often draw upon and reflect the (geo)political dynamics of Europe. It has been noted in several previous works that the tension between national interest and common good permeates the setting up and running of these scientific collaborations (Krige 2003; Hallonsten 2012, 2014; Cramer 2017). However, these considerations do not show any unequivocal trends: they are specific and differ according to the characteristics of each collaboration and negotiation process, such as the scientific purpose, political circumstances, historical context and technical challenges (Hallonsten 2012). 


\section{THE CONCEPT BIG SCIENCE}

In a scholarly context, Big Science was first used in the 1960s, with two different meanings. First, Weinberg $(1961,1967)$, then director of the US-American Oak Ridge National Laboratory, used the concept Big Science (capitalized) to describe what he saw as a worrying development in the organization of R\&D, connected to the Military-Industrial Complex, namely "an increasing subordination of individual scientists under large and bureaucratic projects, with a consequential damage to academic freedom and individual creativity" (Weinberg 1967: 9). Weinberg's argument was based on first-hand experiences from his own organization, the Oak Ridge National Lab, where weapons development and the operation of large infrastructures of modern physics (reactors and particle accelerators) dominated the scene. Second, physicist and historian of science Derek De Solla Price (1963/86) used big science (non-capitalized) to describe a seemingly exponential growth of science in the industrialized world, counted in funding, manpower and output.

Since then, the term and concept Big Science has evolved and become associated with all kinds of things. As noted by Capshew and Rader (1992: 18-19), only very few of the many studies that use "Big Science" in scholarly work relate to the original ideas of Weinberg or Price. Instead, Big Science has become conceptually very flexible and broad, and joined the group of similar popularized uses of the prefix "Big", such as Big Business (Fay 1912; Drucker 1947), Big Government (Pusey 1945), Big Democracy (Appleby 1945), Big Cities (Rogers 1971), Big Foundations (Nielsen 1972) and, most recently, Big Pharma (Law 2006; Ansell 2013) and Big Data (Cukier and Mayer-Schonberger 2013). All of these illustrate phenomena that are claimed to somehow have become big in their own way, in other words, it is postulated, by the use of the prefix, that the size and scale of these things are dramatically different than their prior versions. The fate of Big Science is similar to many of those other examples, namely a conceptual dilution. A broad community of scholars has squeezed all kinds of things into the concept Big Science: the space programs of the 1980s (Smith 1989; Kay 1994), the large corporate R\&D divisions of the 1970s (Hounshell 1992), state-controlled research in the Soviet Union in the early twentieth century (Graham 1992; Kojevnikov 2002), large projects in biology, ecology and geoscience (Aronova et al 2010; Kevles 1997), nineteenth-century naturalist explorer missions to Latin America (Knight 1977) and sixteenth-century astronomy (Christianson 2000), besides the usual suspects of the wartime atomic bomb project in the US (the Manhattan Project) (Hughes 2002), telescopes for ground-based astronomy (McCray 2006) and accelerator complexes for particle physics (Galison et al 1992; Hiltzik 2015) and materials science (Westfall 2008; Hallonsten 2016a). 
Catherine Westfall has adopted a more narrow perspective, arguing that the standard notion of "Big Science began in the radar and atomic bomb projects in World War II, prospered during the Cold War, and showed signs of decline at the end of that era, as signaled by the 1993 cancellation of the multibillion-dollar high-energy physics project the Superconducting Supercollider (SSC)" (Westfall 2003: 33). This view, however, has been challenged by several scholars, including Westfall herself, who have noted that Big Science in an institutional sense did not vanish with the end of the Cold War but rather adapted and took new shapes, to meet new expectations and demands in a post-Cold War era dominated not by nuclear research but advanced materials sciences, molecular biology and life sciences (Hallonsten and Heinze 2012, 2016; Westfall 2008; Jacob and Hallonsten 2012; Hallonsten 2016a; Crease and Westfall 2017). Elzinga concurs, arguing that while national defense was the primary motivation for Big Science in the Cold War era, the recent decades have been characterized by internationalization of science, including Big Science (Elzinga 2012).

Several authors have made attempts to conceptually define Big Science and thus contribute to a detailed and more nuanced understanding of it. The effort of Galison and Hevly (1992), gathering a handful of scholars in an edited book entitled Big Science: The Growth of Large-Scale Research, led to an expanded catalogue of examples but little progress in terms of conceptually framing the available theoretical and empirical work on Big Science as a phenomenon of recent and contemporary science and society. Capshew and Rader (1992) made an exhaustive inventory of the uses of Big Science in scholarly work, and thus produced a conceptual taxonomy with six main areas of the use of the term: (1) a pathological or (2) natural state of science, produced by historical inevitability (cf. Weinberg 1961, 1967; Price 1963/86); the conduct of science (3) with the use of especially big instruments, (4) in especially big ("industrial") organizational arrangements, or (5) in an institutionalized mode tied to contemporary society's need for symbols of progress; and (6) especially politically entangled science. Although their article is a key contribution to the historical contextualization and categorization of different forms of Big Science, it falls short of contributing to a nuanced conceptual framework or theoretical model that could guide contemporary studies and analyses of Big Science outside the history of science.

A recent sociological attempt to remedy this theoretical deficit produced the distinction between a "wide" and "narrow" interpretation of Big Science, where the former includes almost anything that has a connection to science and technology, and is big in one way or the other, and the latter defined in an analysis of some specific contemporary forms of Big Science (Hallonsten 2016a). Temporarily subscribing to this distinction, and dwelling for a moment in the analytical content of the "narrow" interpretation, can yield some insights 
concerning the typical problems of the concept of Big Science and how they can be handled. The "narrow" interpretation of Big Science corresponds to "science made big in three dimensions: big organizations, big machines, and big politics" (Hallonsten 2016a: 17).

Big machines refers to the size of scientific instruments, such as accelerators or telescopes, that often provide the (material) fundament of large-scale research projects. This view on what signifies Big Science is probably most intuitively evident for particle physicists and their increasing circumferences of circular-shaped particle accelerators, which were needed to reach ever higher energies and to explore and study ever smaller constituents of matter. However, alternative uses of accelerators for the production of $\mathrm{x}$-rays and neutron beams that do not need such large circumferences have since long taken over at the expense of particle physics, which is key to the transformation of Big Science (in the "narrow" interpretation) that the definition was invented to assist in analyzing (Hallonsten 2016a: 5ff).

Big organizations means, for instance, the organization of large scientific projects in an industrial manner, or the hierarchical structure of large teams that were formed and organized around a large and costly scientific instrument which was (and still is) the case for e.g. particle physics or ground-based astronomy (Galison and Hevly 1992). This may also point to the increasing amount of financial and human resources devoted to facilitating experimental work, for example the organizations required to operate large instruments and infrastructure.

Yet, as already pointed out, an understanding of Big Science, which is mainly associated with the physical size of scientific instruments and machines and their supporting organizational frameworks, runs the risk of missing other kinds and forms of large-scale research. Moreover, it is difficult to define what counts as "big" compared to what has been large or big in the years and decades before. The US wartime nuclear bomb project, nicknamed the Manhattan Project, employed over 100000 people at its height (Hughes 2002), whereas contemporary Big Science organizations such as the ESRF have permanent workforces of only a few hundred. Particle accelerators, the most ubiquitous examples of Big Science, vary greatly in size depending on areas of use and the historical era in which they were designed and built: The most advanced accelerator projects of the 1950s had circumferences of 50 to 100 meters; two decades later the cutting-edge facilities ran kilometer-long particle accelerators. Today, when the areas of use have shifted to x-rays and neutrons, circumferences and lengths are back at a couple of hundred meters (Hallonsten 2016a: 18-19). Nonetheless, "big machines" and "big organizations" as elements of a definition of Big Science also restricts the empirical scope, which can be useful for reasons of clarity and stringency: The purpose of the cited definitional work was to narrow down the analysis to those Big 
Science endeavors that are physically bound to single infrastructural sites. In order to do useful empirical studies in other distinctly demarcated parts of the very broad spectrum of scientific projects, programs, infrastructures and instrumentation covered by the "wide" interpretation, quite obviously a corresponding degree of clarity and narrowness is necessary in the development of conceptual frameworks to be used for those purposes, albeit of course with the help of other criteria.

Big politics refers to the observation that large-scale research projects require quite substantial political intervention for their realization. Apart from the fact that any investment in scientific research without immediate practical benefit requires investment from the public purse, and thus enters a game of political priority setting, science that is perceived as "Big" is also visible, and positions science on the "maps of politicians and policymakers" (Hackett et al 2004: 748). This also leads to expectations on the political level, not only in relation to national security and geopolitical interest spheres (as during much of the Cold War), but also since science and technology have become increasingly associated with economic growth and competitiveness through the much praised issue of innovation (Berman 2012; Elzinga 2012). In other words, rhetoric to justify the continued investment and political support of Big Science has also been adapted to varying political agendas (Jacob and Hallonsten 2012: 412). After World War II, the beliefs and fears in the powers of nuclear physics seem to have been enough to propel Big Science into its own league of superpower competition, especially after the 1957 Sputnik crisis which extended the expense account of the federal US government significantly, also taking Europe with it in a vast expansion of science budgets across the board, and especially large-scale programs. In the 1960s and 1970s, when social movements protested against the power structures of the political and military establishments, large-scale governmental R\&D and Big Science got its share of criticism. Towards the end of the Cold War, when the US invested heavily in the Strategic Defense Initiative, the SSC and several other projects, Big Science took a place at the centre of politics again (Smith 1990; Gaddis 1982/2005). In the post-Cold War era, when investments in Big Science are seemingly made on the basis of an expectation that they will contribute to gained or increased scientific/technological competitiveness, the political stakes are likewise high (Hallonsten 2016a: 185ff).

The politics of Big Science in Europe is differentiated just like any other area of politics on the continent; there is the national level and the intergovernmental/collaborative level. As discussed above, the traditional approach of European governments has been to regard collaboration and the joint funding and contribution to Big Science projects as a necessity in order to keep a competitive position in relation to the US and Japan, in areas such as astronomy, particle physics and the use of synchrotron radiation and neutrons for studies 
of materials. But larger European countries have also maintained national programs in these areas and continue to operate national Big Science facilities. It is also important to remember, when discussing the big politics of Big Science, that the funding for these projects is miniscule compared to the vast systems of publicly funded R\&D in universities and institutes, which employ tens of thousands of people and share millions of euros every year also in smaller countries. Clearly, there are nuances and a depth in the meaning of "Big Science" that warrants further scholarly analysis, theoretically and empirically.

\section{THE CONCEPT RESEARCH INFRASTRUCTURES}

While there is abundance of the use of Big Science in scholarly works, Research Infrastructures is not a widely used term among historians and sociologists. The first scholarly use of the term seems to be by Papon (2004), and the first comprehensive analysis of the concept, its origins and its use suggests that the origins and motivation for the term root in political need or ambition to (re)brand certain projects and investments to distinguish them from other investments in science and to highlight their boundary-spanning and facilitating nature (Hallonsten 2020a). Meanwhile, contrary to Big Science, there are definitions of RIs available, some of which are also sanctioned by various political organs and governance bodies.

However, concerning definitions, it is important to separate the current use of the term Research Infrastructures by policymakers of the EU and several national governments, and its growing use in scholarly works (see below), from a more general use of "research infrastructure" or plainly "infrastructure" for research, in other instances or further back in time. As already noted, analogous to the suggestion of Capshew and Rader (1992) to separate "Big Science" from "big science", it is possible to distinguish between "Research Infrastructures" as a specific policy concept with wide use especially in the EU's current research and innovation policy work, and "research infrastructures" as a broader term with a general or colloquial meaning, based on a commonplace understanding of "infrastructure" as resources (often physical, but sometimes organizational) necessary for some kind of operation or activity. The definition of "infrastructure" provided by the Oxford Dictionary of English is: "basic physical and organizational structures and facilities [...] needed for the operation of a society or enterprise". Adapting this definition, a general or colloquial meaning of "research infrastructure" could be basic physical and organizational structures and facilities needed for scientific work, which also probably corresponds to the occasional use of "research infrastructure" in a less specific and more colloquial meaning, for example, in Guzzetti's (1995) comprehensive history of European research policy, where the term is 
used once in connection with the general need to build up capacity in Europe after World War II, to keep up in the competition against the US.

But also with this general or colloquial definition, the term and concept "research infrastructure" is conspicuously absent from historical works that deal with basic physical and organizational structures and facilities needed for science, such as particle accelerators, astronomical observatories, and other larger equipment. The history of science is filled with accounts on, and analyses of, the planning, funding, construction, operation and use of such "research infrastructures" without ever using this term (see e.g. Cathcart 2006; Strasser 2011; Nye 1996; Livingstone 2003; Agar 2012; Kevles 1977/95; Pais 1986; Martin 2018; Mody 2011). The key works that identify, classify and define the use of large equipment and instrumentation in science do not use the term at all (e.g. Capshew and Rader 1992; Galison and Hevly 1992; Westfall 2003). Thus we can conclude that in the general meaning, and without capitalization, "research infrastructures" is really not a distinct term and concept at all. The reason is probably that any analytical effort that attempts to build on a general definition of "research infrastructure", for instance the one obtained by the adaptation of the definition of "infrastructure" from the Oxford Dictionary of English (above), yields a concept and term which is unworkably vague: anything can be a research infrastructure and a research infrastructure can be anything. Indeed, the laptop used to write this text, the funding body that provided support for this book project and the collection of books and articles cited in this chapter and throughout this book are all physical or organizational "research infrastructures" in a wide meaning.

Moving on to "Research Infrastructures" as a concept of policy origin, there is much to suggest that the raison d'être of this concept lies (so far) in political convenience, opportunism or necessity, rather than the identification of a clearly marked organizational field or sector of any national or international science and innovation system. Until recently, the concept "Research Infrastructures" has been used solely in a European context. RIs have been declared a "pillar" of the ERA strategy by the European Commission and "the key drivers for European capacity building" (European Commission 2008: 9, 15). ESFRI, which was established in 2002 "to support a coherent and strategy-led approach to policy making on [RIs] in Europe" (ESFRI 2016: 4), highlights the strategic importance of RIs for science and innovation in Europe, claiming that they "provide unique opportunities for world-class research and training" (ESFRI 2006: 10). ESFRI also stresses that RIs are "vital to make the European Research Area attractive at a global level" (ESFRI 2008: 5), and that they are "a key instrument in attracting and bringing together researchers, funding agencies, politicians and industry to act together and tackle the cross-disciplinary scientific and technical issues of critical importance for our continued prosperity and quality of life" (ESFRI 2010: 7). 
ESFRI's definition of RIs is "facilities, resources or services of a unique nature that have been identified by European research communities to conduct top-level activities in all fields" (ESFRI 2010: 7). This is clearly a political rather than analytical definition: Few, if any, of the projects listed in the ESFRI roadmaps are "unique" in the original sense of the word, but have direct counterparts and competitors in the US and Japan, and also across Europe. These counterparts and competitors may, in certain aspects, outperform the ESFRI-listed projects, which also means that "top level" is imprecise and normative or politically motivated rather than descriptive. Moreover, while the ESFRI roadmaps and the lists of projects included in them have been drafted in peer-review committees consisting of top representatives of scientific communities, it is not clear either from the roadmaps or from the definition itself whether any political prioritization process has also been involved. In other words, it is unclear if the projects listed in the roadmaps have been selected solely on the basis of a stringent evaluation of performance or potential according to specific criteria or functions, sizes or reaches in use; what exactly these criteria are; or how they have been established (Bolliger and Griffiths, ch 5 in this volume).

Clearly, the EU places great trust, at least rhetorically, in the capacity of RIs to be key loci of cross-border collaboration in European science and innovation, and key drivers of an enhancement of research and innovation in service of the common market and to solve current and future challenges to sustainability, health and quality of life. Similar statements can be found in the several roadmap documents and reports developed and published by governments and research funding agencies in a handful of European countries, including Germany (BMBF 2013), Sweden (Swedish Research Council 2008) and Denmark (Strategiske Forskningsråd 2005) (see Bolliger and Griffiths, ch 5 in this volume).

The popularity of the term and concept Research Infrastructures in this EU-related context links to the increasing importance that science policy documents, such as reports from ESFRI and the Organisation for Economic Co-operation and Development's (OECD) Global Science Forum, attribute to the role of research infrastructures (non-capitalized) for economic competitiveness. In 2000, the EU launched its "Lisbon Strategy" with new directions to the economic policy of the EU and the strategic goal that Europe should "become the most competitive and dynamic knowledge-based economy in the world, capable of sustainable economic growth with more and better jobs and greater social cohesion" by 2010. The Lisbon strategy endorsed the ERA initiative that had been launched two months before and that can be interpreted as a "third generation" of EU policy involvement in science and innovation, corresponding to a transition from science policy (first generation) to technology policy (second generation), and finally to innovation policy (Borrás 2003). The 
approach to RIs in the ERA framework is based on the objective to consolidate common resources to conduct research, not only in natural sciences, but also in other fields such as the humanities and social sciences. One goal of ERA is to "develop world-class research infrastructures" and to "optimise the use and development of the best research infrastructures existing in Europe" (European Commission 2008). The several initiatives in the years thereafter, including the creation of ESFRI and its publication of several consecutive roadmaps, the funding programs for RIs within the Framework Programmes and the creation of the ERIC organizational form by EU regulation in 2009, should be seen in light of the very ambitious goals for RIs laid down in the ERA policies (see above and Ulnicane, ch 4 in this volume; Bolliger and Griffiths, ch 5 in this volume; Moskovko, ch 6 in this volume).

Approaching the same issue from another angle, there is much to suggest that the political hype in Europe and the EU around RIs in the past two decades is largely due to new patterns of research funding and organization. With the increased competition for funds and the "economization" (Berman 2014) and "commodification" (Radder 2010) of academic science, block-grant funding to universities and other research environments has been replaced with line-item funding with strings attached and tighter control mechanisms for resource utilization. Among other things, this has meant the downsizing of many of the resources built, maintained and operated internally at university faculties, departments and institutes, such as larger laboratory equipment, instrumentation for analysis, databases and sample repositories, but also (comparably) smaller particle accelerator facilities and similar. In order to secure funding for these technical assets, that are absolutely crucial for much scientific work, and in order to secure sustainable organizational arrangements for their maintenance, development and use, specific funding programs and specific policy instruments needed to be put in place. From the side of the projects and practitioners, it can be noted that several of the RIs on the ESFRI roadmap are of a size and scope that typically would have made them into parts of academic environments or institutes some decades ago, which the science funding systems of the time also enabled.

A prime example is the European Social Survey, initiated by the European Science Foundation in 1996 to enable the pan-European biannual collection and handling of data on social issues, and operated by a network of universities and institutes in Europe. The European Social Survey was struggling with organizational framework and the lack of a stable and sustainable funding solution until it was included in the 2006 ESFRI roadmap with an estimated "construction cost" of $€ 9$ million to cover for the setting up of a more robust organization and funding structure. In 2013, the European Social Survey became an ERIC (Duclos Lindstrøm and Kropp 2017). It is quite clear that the project's identification as a "research infrastructure" in the social sciences, and 
its consecration to the status of a European research infrastructure (see below), in other words of "unique nature" and "identified by European research communities to conduct top-level activities" (ESFRI 2010: 7), was used by its managers and champions to rescue the project and secure a longer-term and more stable funding structure (Duclos Lindstrøm and Kropp 2017: 861).

The variety within the collection of 60 facilities, databases, networks, vessels, etc. that have been listed on any of the four editions of the ESFRI roadmap to date, and/or that have been granted ERIC status by the European Commission, is huge: We find here the ESS and European XFEL, both single-sited, accelerator-based facilities (and prime examples of what has been called "transformed" Big Science, see above) with construction costs close to $€ 2$ billion; the European Social Survey, which is a data collection exercise and repository of significantly smaller size and no physical infrastructure; the Integrated Carbon Observation System and the European Multidisciplinary Seafloor and Water Column Observatory which are collections of utilities for the observation of various patterns of environmental change and the Central European Research Infrastructure Consortium which is only a network of pre-existing research facilities that coordinates experimental work and provides users with a single entry point. As shown in further detail by Hallonsten (2020a) and Moskovko (ch 6 in this volume), these projects and organizations differ greatly in several respects: size, cost, organizational form, user communities, scientific areas served and the breadth and size of these.

The question remains what the criteria are for identifying projects and organizations as RIs, and who decides. The costliest of all RIs listed in an ESFRI roadmap document and/or granted ERIC status is the ESS, under construction in southern Sweden. It is certainly, by most relevant standards, possible to identify as Big Science, and nowadays it also has "Research Infrastructure" in its official name, since it is an ERIC, but it did not self-identify as a "research infrastructure" but rather "research facility" in its annual reports up until the application for ERIC status in 2015. Nonetheless, it has been listed in all the ESFRI roadmaps and in all editions of the Swedish national roadmap (e.g. Swedish Research Council 2008). Meanwhile, there are of course several resources of various types and in many different organizational settings that would qualify as "research infrastructures" simply by being identical or very similar to the projects on the ESFRI roadmap (or any national roadmap of a European country) and by fulfilling the very general definitions cited above, but that do not self-identify as such and/or have not been branded as such by ESFRI or the European Commission or any national policymaking body.

Contrary to Big Science - which is a vague and broad term and concept because scholars and policymakers have been in the habit of using it for whatever purposes they want - Research Infrastructures in the narrower, political sense (and capitalized) therefore appears as binary: Either you're 
self-identifying, or branded by someone else, as RI, or you are not. This binarity seems largely detached from any analytically useful categorizations of size, cost, organizational forms, use, communities and so on - also here, anything can be a Research Infrastructure and a Research Infrastructure can be anything, provided that the label is affixed to this anything. ESFRI, the European Commission and several national bodies (see Bolliger and Griffiths, ch 5 in this volume) have the ability to consecrate almost anything to a status of RI. The origin of the term consecration is in the Roman Catholic Church where it literally means "association with the sacred", in other words the rite of making something holy. It was first used in a sociological context by Bourdieu (1975, 1988) to denote the inclusion of individuals in scientific elites by the awarding of several forms of social recognition, and more recently by Holmqvist (2017) in a study of how people become part of social elites in Sweden. The reader is well served by bearing in mind, when proceeding through the collection of chapters that makes up this book, that such consecration of a project does not mean either membership in any specific association or field of entities or organizations, or that the project automatically fulfils some predefined criteria. "RI" is a label, just like "Big Science" and it can be used on almost anything, provided that there is a will to do so.

\section{CONCEPTUAL LANDSCAPE}

An important question has been lurking in the background of the previous sections, namely how the concepts Big Science and RIs relate to each other. The issue is not easily resolved; the analytical vagueness and availability of different interpretations depending on viewpoint and ambitions makes the task of positioning the two in some analytical relationship thorny. In a most rudimentary sense (and keeping the concepts non-capitalized), it can be concluded that some research infrastructures are big science, whereas some are not, at least not relative to others. It can also be noted that the term Research Infrastructures (capitalized) has so far been used mostly in a European context, which means that based on the argument about binarity and consecration at the end of the previous section, many US-American facilities and projects should not be branded as RIs even if their direct European counterparts are. In principle, the same is true also for any other example where the term research infrastructure (non-capitalized) or Research Infrastructure (capitalized) is not used, such as in those countries where roadmaps identify "large facilities" or "large equipment" or similar but, for any reason, avoid calling them "research infrastructures".

Big Science and RIs most evidently overlap where large facilities such as particle accelerators are used for scientific research by a community that extends beyond the inhouse scientists of the organization that operates the 
facilities: ESRF and the European XFEL are prime examples (Cramer 2020). Second, there are cases of Big Science that are (probably) not RIs. The Human Genome Project, undertaken in 1990-2003, has been called Big Science and compared to the SSC by Kevles (1997), but was certainly not an RI (although it made use of vast instrumentation) but rather a research project. Third, there are cases of RIs that are not big science which is more difficult to define since "big" in the wide interpretation of "big science" is relative and a very inclusive concept. But it may well be argued that the European Social Survey (see previous section) is not at all big science, to say nothing of the many smaller projects that national RI roadmaps frequently highlight and that are minuscule in size and cost.

Other concepts have been in sway in the communities that have studied big science and research infrastructures, most notably "megascience" which has at least two meanings. First, there was the OECD Megascience Forum which was a discussion forum like ESFRI, organized by the OECD that met regularly between 1992 and 1999 to foster cooperation among OECD countries in the planning, construction and operation of large research facilities. It is not clear why the forum used the term "megascience" and not simply "big science", but it is probably not a far-fetched guess that the reasons were rhetorical and political. There were also no clear definitions, and so "megascience" in this context was, like "Research Infrastructures", a politically motivated term. Second, "megascience" has also been used with a sociological/analytical meaning. The history of Fermilab, the US-American flagship particle physics facility in Illinois, inaugurated in 1972, was chronicled and analyzed by Hoddeson et al (2008) who identified the transition of particle physics in the 1970s into a new state as a move from "big science" to "megascience". The development had a micro and a macro component, interrelated of course. On the micro level, the experiments in particle physics grew complex, and stretched out in time, to the degree that instrumentation became too big and costly for ordinary research groups to fund and operate, which led to the growth of teams to hundreds (and later thousands) of researchers and engineers, and the prolongation of experiments for several years. The macro-level development came from the need to concentrate resources to fewer facilities and lab organizations, given the slowdown of economic growth in the early 1970s and the dramatic increase in the size and cost of particle physics facilities and instruments. The "megascience" development has continued; if the gargantuan SSC would not have been cancelled by the US Congress in 1993, it would certainly have monopolized the US federal particle physics budget and produced the closedown of similar activities at Fermilab and elsewhere. In the early 2000s CERN completed its construction of the Large Hadron Collider, with involvement by US-American, Japanese, Chinese and Russian particle physicists, and became the only particle physics laboratory in the world that operates a major experimental facility. 
The above described micro-level "megascience" trend is also manifested at CERN; the two publications that announced the discovery of the Higgs boson in 2012 (with the use of the Large Hadron Collider) had close to 3000 authors each - experiment teams in "megascience" are nowadays counted not by the hundreds, but by the thousands. But this is a phenomenon isolated to particle physics - no other science has had a similar development, and other forms of Big Science are still serving teams of researchers by the size of five to ten, or occasionally, 40-50 (Hallonsten 2016a: 100). It can, hence, be concluded that "megascience", at least in the analytical meaning of the word as developed by Hoddeson et al (2008) and further refined by Hallonsten (2016a: 62-4), is a particle physics phenomenon.

A related concept is "megaprojects", which has gotten its own subspecialism of macrosociology, much by the work of Flyvbjerg (2003, 2008, 2014, 2017). The literature on megaprojects is rich in detail and analytical ambitions, but never deals specifically with megaprojects in science, although at least some of the projects typically identified as Big Science, and some of the largest projects consecrated to RI status by ESFRI and the European Commission, certainly fit the definition of megaproject as provided by Flyvbjerg (2017: 2): "large-scale, complex ventures that typically cost $\$ 1$ billion or more, take many years to develop and build, involve multiple public and private stakeholders, are transformational, and impact millions of people". Save for the final part - Big Science projects do not impact millions of people other than in an indirect sense, by their general contributions to scientific progress and thus, by extension, to society - this definition applies to the typically mentioned "classics" of Big Science in Europe, if the $\$ 1$ billion threshold is adjusted for inflation: CERN, ESO, ILL, ESRF, XFEL and ESS. Importantly, however, it does not apply to most RIs, which is yet another reminder of the enormous variety within the field of projects, organizations and entities that this book is about. The chapter by Hallonsten (ch 10 in this volume) explores the (dis)similarities between "megaprojects" and Big Science or RIs further, by analyzing if Flyvbjerg's "iron law" of megaprojects - that they always exceed budgets and timetables - holds for Big Science.

It is also necessary to mention some of the juxtapositions of the concepts - a major theme in the analysis that produced the conceptualization of "transformed Big Science" (Hallonsten 2016a) was the identification that a lot of contemporary big science is really "small science on big machines", i.e. that contrary to the developments in particle physics that has been conceptualized as "megascience" (above), the currently most extensive use of particle accelerators is for the production of x-rays and neutrons which are experimental resources used by ordinary research groups from universities, institutes and, occasionally, industrial firms, which are of quite ordinary sizes and only use $\mathrm{x}$-rays and neutrons (and thus the instrumentation at the Big Science facilities 
to which they travel for shorter visits) as resources among several others, not least including laboratory equipment in their home organizations. It deserves to be noted that the disciplinary breadth of these user communities is wide and growing, and that especially applications in biology and the life sciences have grown tremendously since the early 1990s (Hallonsten 2016b).

Although this conceptualization of a "transformed Big Science" builds on the "narrow" interpretation (see above) and thus restricts itself to the use of particle accelerators and reactors for experimental science, there is certainly a connection to be made to RIs. One of the things that many of the entities and projects consecrated to the status of RIs by the EU or national actors have in common is that they are resources for scientific research used by quite ordinary research groups in universities, institutes and industrial firms. This, furthermore, seems to fit quite well with the policy objectives of ESFRI, namely to let RIs "provide unique opportunities for world-class research and training" (ESFRI 2006: 10). This should also be borne in mind in the following - part of the continued success of Big Science beyond the Cold War context, and the rise of RIs as a relevant policy concept, lies in the broadening of the uses of Big Science to new scientific fields with clearer and more direct practical applications.

\section{THE BOOK}

The collection of chapters that make up this book have been written by scholars across Europe who share an interest in the topics of Big Science and RIs as outlined in the previous sections, and a determination to advance and improve our understanding of these issues by adding more stringent scholarly analysis.

Nicolas Rüffin's effort, in Chapter 2, is a model for everyone with such ambitions. In his well-needed and unprecedented review of methods and approaches in the very amorphous field of study that this book writes itself into, he provides a comprehensive literature list which in itself is a formidable contribution, but also an analysis of the field as such, based on approaches thus far tried. Important and interesting to note is also the reconciliatory effort made by Rüffin in this chapter concerning the incoherencies and contradictions in studies on Big Science and RIs in terms of theoretical and empirical scope and focus. The pragmatic solution to the complicating variety of cases and categories of Big Science and RIs that he offers when pointing to the need of openness and flexibility in order to learn and gain deeper and broader knowledge is instructive.

Chapter 3, by Katharina Cramer, deepens and widens the historical context of Big Science and RIs by demonstrating how the pursuit of scientific and technological excellence in Europe in the twentieth century has taken place within the framework of a broader political development of integration lined 
with crises and successes. The political integration process of Europe since World War II has been mirrored in the history of collaborative Big Science in Europe and the several projects highlighted by Cramer in her chapter have been very much shaped by their times, but also sometimes functioned as political and diplomatic spearheads for political developments with far broader importance and meaning.

In Chapters 4, 5, and 6, the role of the EU in the two most recent decades of research and innovation policy generally, and RI policy specifically, is analyzed in depth. Chapter 4, by Inga Ulnicane, discusses both the overall level of top EU initiatives and ambitions with a general ambition, and how these have played out on the level of a specific case, the Human Brain Project. Chapter 5, by Isabel Bolliger and Alexandra Griffiths, chronicles the genesis and development of ESFRI and its roadmap, and also provides a survey of the landscape of RI roadmapping processes in national contexts in Europe. In Chapter 6, Maria Moskovko traces the origins of the ERIC regulation and the entirely new ERIC organizational form, and also discusses how it has acted out in practice, in a comprehensive survey of the 21 ERICs that exist to date.

Chapter 7, by Thomas Franssen, is a much-needed case study of RIs in the humanities. Franssen shows, with the help of a competent analysis of policymaking in the Netherlands in the past few decades, how the concept of RIs has been used as a policy tool, to revitalize the area of humanities by steering its focus towards tangible (and thus measurable) activities that, from a policymaker's point of view, appear as more useful or relevant. The chapter fulfills the dual purpose of giving a crucial insight into how RI policy functions in the area of humanities, and how RI funding is used as a policy instrument.

Chapters 8-11 each deal with different aspects of Big Science and RIs that are all highly relevant and explanatory in the context of this book. Chapter 8, by Olof Hallonsten, Hjalmar Eriksson, and August Collsiöö, argues that RIs should not be handled in policy or funding contexts as scientific production units on par with university departments or institutes, since their role is essentially different. With the use of the classic sociological concept of functional differentiation, and an in-depth case study of a research infrastructure (non-capitalized) that has been around since the 1950s, the authors of this chapter make the case that a systems view on innovation enables the identification of RIs as a distinct type of resource or unit that needs to be handled as such in policymaking. Chapter 9, by Andrew Williams and Jean-Christophe Mauduit, takes a comprehensive grip on the issue of access for researchers to RIs and how this relates to national and international policy considerations and, crucially, the issue of socio-economic impact and usefulness of Big Science and RIs. As they show, the issue of access is not only absolutely vital, but indeed the basic raison d'être for the existence of these RIs, and therefore a topic in great need of analysis. Chapter 10, by Olof Hallonsten, 
applies the concept of "megaprojects" and the "iron law" of cost and timetable overruns of "megaprojects" on Big Science and RIs, using this as the basis for a discussion on the challenges built into the very heterogeneous planning processes and long time horizons that characterize Big Science projects. Similarly taking a longer time perspective, Chapter 11, by Beatrice D'Ippolito and Charles-Clemens Rüling, shows how a Big Science facility can manage to renew itself and maintain a central position in an international (European) scientific community, also contrasting this role as stable and enduring center of gravity for a dynamic and changeable user community with technical limitations and what this means for the life cycle of the RI. The chapter also demonstrates how an RI can remain the center of, and to some extent engine of, a broad and inclusive European user community, thus to some extent also lending substance to the claim that RIs can be "the key drivers for European capacity building" (European Commission 2008: 15).

Such substance to otherwise comparably hollow claims is one of the main aims of this book. The concluding chapter will reflect on the fulfillment of this aim and summarize the main findings, so that the reader is oriented in the state of the art of the study of Big Science and RIs in Europe, established or updated by the collected chapters in the book, to the benefit of scholars, policymakers and the interested public.

\section{REFERENCES}

Agar J (2012) Science in the twentieth century and beyond. Polity Press.

Ansell J (2013) Transforming big pharma. Gower Publishing.

Appleby P H (1945) Big democracy. Knopf.

Aronova E, K S Baker and N Oreskes (2010) Big science and big data in biology: From the international geophysical year through the international biological program to the Long Term Ecological Research (LTER) network, 1957-present. Historical Studies in the Natural Sciences 40 (2): 183-224.

Berman E P (2012) Creating the market university: How academic science became an economic engine. Princeton University Press.

Berman E P (2014) Not just neoliberalism: Economization in US science and technology policy. Science, Technology, and Human Values 39 (3): 397-431.

Blaauw A (1991) ESO's early history. ESO.

BMBF (2013) Roadmap for research infrastructures: A pilot project of the Federal Ministry of Education and Research (BMBF). Available at https://ec.europa.eu/ research/infrastructures/pdf/roadmaps/germany_national_roadmap_en.pdf (last accessed December 15, 2019).

Borrás S (2003) The innovation policy of the European Union: From government to governance. Edward Elgar Publishing.

Bourdieu P (1975) The specificity of the scientific field and the social conditions of the progress of reason. Social Science Information 14 (6): 19-47.

Bourdieu P (1988) Homo academicus. Stanford University Press. 
Capshew J H and K A Rader (1992) Big science: Price to the present. Osiris 2nd series, 7: $3-25$.

Cathcart B (2006) The fly in the cathedral. Farrar Straus and Giroux.

Christianson J R (2000) On Tycho's island: Tycho Brahe, science, and culture in the sixteenth century. Cambridge University Press.

Cramer K C (2017) Lightening Europe: Establishing the European Synchrotron Radiation Facility (ESRF). History and Technology 33 (4): 396-427.

Cramer K C (2020) A political history of Big Science: The other Europe. Palgrave Macmillan.

Crease R and C Westfall (2017) The new Big Science. Physics Today 69 (5): 30-6.

Cukier K and V Mayer-Schonberger (2013) Big data: A revolution that will transform how we live, work and think. Murray.

D'Ippolito B and C-C Rüling (2019) Research collaboration in Large Scale Research Infrastructures: Collaboration types and policy implications. Research Policy 48: 1282-96.

Drucker P F (1947) Big business. Heinemann.

Duclos Lindstrøm M D and K Kropp (2017) Understanding the infrastructure of European Research Infrastructures: The case of the European Social Survey (ESS-ERIC). Science and Public Policy 44 (6): 855-64.

Elera Á De (2006) The European Research Area: On the way towards a European scientific community? European Law 12 (5): 559-74.

Elzinga A (2012) Features of the current science policy regime. Science and Public Policy 39 (4): 416-28.

Elzinga A and A Jamison (1995) Changing policy agendas in science and technology. In S Jasanoff, G E Markle, J C Petersen and T Pinch (eds) Handbook of science and technology studies. Sage, pp 572-97.

ESFRI (2006) Strategy report on research infrastructures. Roadmap 2006.

ESFRI (2008) Strategy report on research infrastructures. Roadmap 2008.

ESFRI (2010) Strategy report on research infrastructures. Roadmap 2010.

ESFRI (2016) Strategy report on research infrastructures. Roadmap 2016.

European Commission (2008) Developing world-class research infrastructures for the European Research Area (ERA): Report of the ERA expert group. Office for Official Publications of the European Communities.

European Council (2009) Council Regulation No 723/2009 of 25 June 2009 on the Community legal framework for a European Research Infrastructure Consortium (ERIC) [2009] OJ L 206/1, as later amended by Council Regulation (EC) No 1261/2013 of 2 December 2013 [2013] OJ L 326/1.

Fay C N (1912) Big business and government. Moffat, Yard and Co.

Flyvbjerg B (2003) Megaprojects and risk: An anatomy of ambition. Cambridge University Press.

Flyvbjerg B (2008) Decision-making on mega-projects: Cost-benefit analysis, planning and innovation. Edward Elgar Publishing.

Flyvbjerg B (2014) Megaproject planning and management: Essential readings. Edward Elgar Publishing.

Flyvbjerg B (2017) The Oxford handbook of megaproject management. Oxford University Press.

Gaddis J L (1982/2005) Strategies of containment: A critical appraisal of American national security policy during the Cold War, 2nd ed. Oxford University Press.

Galison P and B Hevly (eds) (1992) Big science: The growth of large-scale research. Stanford University Press. 
Galison P, B Hevly and R Lowen (1992) Controlling the monster: Stanford and the growth of physics research, 1935-1962. In P Galison and B Hevly (eds) Big science: The growth of large-scale research. Stanford University Press, pp 46-77.

Giroux HA(2007) Theuniversityin chains: Confronting themilitary-industrial-academic complex. Paradigm Publishers.

Graham L R (1992) Big science in the last years of the Soviet Union. Osiris 2nd series 7: 49-71.

Greenberg D (1967/99) The politics of pure science, 2nd ed. University of Chicago Press.

Guston D H (2000) Between politics and science: Assuring the integrity and productivity of research. Cambridge University Press.

Guzzetti L (1995) A brief history of European Union research policy. European Communities.

Hackett E, D Conz, J Parker, J Bashford and S DeLay (2004) Tokamaks and turbulence: Research ensembles, policy and technoscientific work. Research Policy 33: 747-67.

Hallonsten O (2012) Continuity and change in the politics of European scientific collaboration. Journal of Contemporary European Research 8 (3): 300-19.

Hallonsten O (2014) The politics of European collaboration in Big Science. In M Mayer, M Carpes and R Knoblich (eds) The global politics of science and technology, Vol. 2. Springer, pp 31-46.

Hallonsten O (2016a) Big Science transformed: Science, politics and organization in Europe and the United States. Palgrave Macmillan.

Hallonsten O (2016b) Use and productivity of contemporary, multidisciplinary Big Science. Research Evaluation 25 (4): 486-95.

Hallonsten O (2020a) Research Infrastructures in Europe: The hype and the field. European Review 28 (4): 617-35.

Hallonsten O (2020b) The campaign: How a European Big Science facility ended up on the peripheral farmlands of southern Sweden. Arkiv Academic Press.

Hallonsten $\mathrm{O}$ and $\mathrm{T}$ Heinze (2012) Institutional persistence through gradual adaptation: Analysis of national laboratories in the USA and Germany. Science and Public Policy 39: 450-63.

Hallonsten O and T Heinze (2016) "Preservation of the laboratory is not a mission". Gradual organizational renewal in national laboratories in Germany and the United States. In T Heinze and R Münch (eds) Innovation in science and organizational renewal: Historical and sociological perspectives. Palgrave Macmillan, pp 117-45.

Heinze T, O Hallonsten and S Heinecke (2015a) From periphery to center: Synchrotron radiation at DESY, Part I: 1962-1977. Historical Studies in the Natural Sciences 45 (3): 447-92.

Heinze T, O Hallonsten and S Heinecke (2015b) From periphery to center: Synchrotron radiation at DESY, Part II: 1977-1993. Historical Studies in the Natural Sciences 45 (4): 513-48.

Heinze T, O Hallonsten and S Heinecke (2017) Turning the ship: The transformation of DESY, 1993-2009. Physics in Perspective 19: 424-51.

Hermann A, J Krige, U Mersits and D Pestre (eds) (1987) History of CERN. Volume I: Launching the European organization for nuclear research. North-Holland.

Hermann A, J Krige, U Mersits and D Pestre (eds) (1990) History of CERN. Volume II: Building and running the laboratory, 1954-1965. North-Holland.

Hiltzik M (2015) Big science: Ernest Lawrence and the invention that launched military-industrial complex. Simon and Schuster. 
Hoddeson L, A Kolb and C Westfall (2008) Fermilab: Physics, the frontier, and megascience. University of Chicago Press.

Holmqvist (2017) Leader communities: The consecration of elites in Djursholm. Columbia University Press.

Hounshell D A (1992) Du Pont and the management of large-scale research and development. In P Galison and B Hevly (eds) Big Science: The growth of large-scale research. Stanford University Press.

Hughes J (2002) The Manhattan project: Big Science and the atom bomb. Icon Books.

Jacob M and O Hallonsten (2012) The persistence of Big Science and megascience in research and innovation policy. Science and Public Policy 39: 411-15.

Jacrot B (2006) Des neutrons pour la science: Histoire de l'Institut Laue-Langevin, une coopération internationale particulièrement réussie. EDP Sciences.

Kay W D (1994) Democracy and super technologies: The politics of the space shuttle and space station freedom. Science, Technology, and Human Values 19: 131-51.

Kevles D J (1977/95) The physicists: The history of a scientific community in modern America. Harvard University Press.

Kevles D J (1997) Big Science and big politics in the United States: Reflections on the death of the SSC and the life of the Human Genome Project. Historical Studies in the Physical Sciences 27 (2): 269-97.

Knight D M (1977) The nature of science: The history of science in Western culture since 1600. Deutsch.

Kojevnikov A (2002) The Great War, the Russian Civil War, and the invention of big science. Science in Context 15 (2): 239-75.

Krige J (ed) (1996) History of CERN, Vol. III. North-Holland.

Krige J (2003) The politics of European scientific collaboration. In J Krige and D Pestre (eds) Companion to science in the twentieth century. Routledge, pp 897-918.

Krige J (2006) American hegemony and the postwar reconstruction of science in Europe. MIT Press.

Krige J and L Guzzetti (eds) (1997) History of European scientific and technological cooperation. European Communities.

Law J (2006) Big pharma: How the world's biggest drug companies control illness. Carroll and Graf.

Livingstone D N (2003) Putting science in its place: Geographies of scientific knowledge. University of Chicago Press.

Madsen C (2012) The jewel on the mountaintop: The European Southern Observatory through fifty years. Wiley.

Martin J (2018) Solid state insurrection: How the science of substance made American physics matter. Pittsburgh University Press.

McCray W P (2006) Giant telescopes: Astronomical ambition and the promise of technology. Harvard University Press.

Misa T and J Schot (2005) Inventing Europe: Technology and the hidden integration of Europe. History and Technology 21 (1): 1-19.

Mody C (2011) Instrumental community: Probe microscopy and the path to nanotechnology. MIT Press.

Moskovko M, A Astvaldsson and O Hallonsten (2019) Who is ERIC? The politics and jurisprudence of a governance tool for collaborative European research infrastructures. Journal of Contemporary European Research 15 (3): 249-68.

Nielsen W (1972) The big foundations. Columbia University Press.

Nye M J (1996) Before Big Science: The pursuit of modern chemistry and physics, 1800-1940. Harvard University Press. 
Pais A (1986) Inward bound: Of matter and forces in the physical world. Oxford University Press.

Papon P (2004) European scientific cooperation and research infrastructures: Past tendencies and future prospects. Minerva 42 (1): 61-76.

Papon P (2009) Intergovernmental cooperation in the making of European research. In $\mathrm{H}$ Delanghe, U Muldur and L Soete (eds) European science and technology policy: Towards integration or fragmentation? Edward Elgar Publishing, pp 24-43.

Papon P (2012) L'Espace Européen de la Recherche (1960-1985): Entre science et politique. In C Defrance and U Pfeil (eds) La construction d'un Espace Scientifique Commun? La France, la RFA et l'Europe après le "Choc du Spoutnik”. P I E Peter Lang, pp 37-54.

Pestre D (1997) Prehistory of the Franco-German Laue-Langevin Institute. In J Krige and L Guzzetti (eds) History of European scientific and technological cooperation. Office for Official Publications of the European Communities, pp 137-44.

Peterson J (1997) Eureka: A historical perspective. In J Krige and L Guzzetti (eds) History of European scientific and technological cooperation. Office for Official Publications of the European Communities, pp 323-45.

Price, D dS (1963/86) Little science, big science ... and beyond. Columbia University Press.

Pusey M J (1945) Big government: Can we control it? Harper \& Bros.

Radder H (ed) (2010) The commodification of academic research: Science and the modern universities. Harvard University Press.

Rogers D (1971) The management of big cities, interest groups, and social change strategies. Sage.

Roland J-L (1997) COST: An unexpected successful cooperation. In J Krige and L Guzzetti (eds) History of European scientific and technological cooperation. Office for Official Publications of the European Communities, pp 355-68.

Simoulin V (2012) Sociologie d'un grand équipement scientifique: Le premier synchrotron de troisième génération. ENS Éditions.

Smith B (1990) American science policy since World War II. Brookings.

Smith R W (1989) The space telescope: A study of NASA, science, technology, and politics. Cambridge University Press.

Strasser B (2011) The experimenter's museum: GenBank, natural history, and the moral economies of biomedicine. Isis 102: 60-96.

Strategiske Forskningsråd (2005) Fremtidens forskningsinfrastruktur - kortlægning af behov og forslag til strategi. Baggrundsrapport.

Swedish Research Council (2008) Swedish Research Council's guide to the infrastructure. Swedish Research Council.

Tindemans P (2009) Post-war research, education and innovation policy-making in Europe. In H Delanghe, U Muldur and L Soete (eds) European science and technology policy: Towards integration or fragmentation? Edward Elgar Publishing, pp 3-23.

Weinberg A (1961) Impact of large-scale science on the United States. Science 134 (3473): 161-4.

Weinberg A (1967) Reflections on big science. Pergamon Press.

Westfall C (2003) Rethinking big science: Modest, mezzo, grand science and the development of the Bevalac, 1971-1993. Isis 94: 30-56.

Westfall C (2008) Surviving the squeeze: National laboratories in the 1970s and 1980s. Historical Studies in the Natural Sciences 38 (4): 475-78. 